\title{
Study on Cultural and Creative Design of Traditional Chinese Calligraphy Tools in Digital Era
}

\author{
Shunmei Lin $^{1, *}$ Xue Ban ${ }^{1}$ \\ ${ }^{1}$ Xiammen Huaxia University, Xiamen, Fujian 361000, China \\ *Corresponding author. Email: 57051686@qq.com

\begin{abstract}
This paper analyzes the creative product design concept of traditional Chinese calligraphy tools (writing brushes, ink sticks, paper and inkstones) in the context of the new digital media era, as well as the development and practice methods of creative products. It explores how to present the design expression in accordance with the modern aesthetic elements in the design, and points out the practical importance of the design and development of the traditional Chinese calligraphy tools through a large number of data research and combining with the use habits and aesthetic habits of modern people. The author also looks into the design prospect of cultural and creative products.
\end{abstract}

\section{Keywords: digital era, traditional Chinese calligraphy tools, cultural and creative design}

\section{INTRODUCTION}

Calligraphy art and culture boasts a long history in the traditional Chinese culture of calligraphy. Calligraphy, as the intangible cultural heritage of the world and one of the "four quintessence" of the Chinese nation (traditional Chinese calligraphy tools), has a distinctive lyrical character, so it has become a magic weapon for many generations of literati. "To do his work well, one must first sharpen his tools", a necessary tool for Chinese calligraphy creation, the traditional Chinese calligraphy tools (writing brushes, ink sticks, paper and inkstones) play an important role in the cultural heritage of calligraphy. Therefore, the traditional Chinese calligraphy tools in China are closely related to Chinese culture. If we go back to the Song Dynasty (The song dynasty (960-1279) was a dynasty in Chinese history. It was divided into the northern and southern song dynasties and lasted for 319 years under the rule of 18 emperors), we can see the poet Mei Yaochen's verse that "the traditional Chinese calligraphy tools are in your two counties. Recently, I play with and appreciate writing brush, ink stick, paper and inkstone you gave me", from which we can see that scholars are really full of appreciation and love for the traditional Chinese calligraphy tools.

The continuous development of society has brought the arrival of the digital era, followed by the earth shaking changes in the way of information dissemination, more and more new media and communication technology continue to appear in people's daily life, at the same time, the speed of information dissemination is also becoming increasingly faster, and people's requirements for the quality of information dissemination services are also on the rise. Against the background of this era, how to make the traditional "four treasures of study" design in the new era give out a new era charm, and how to use the aesthetic in line with the contemporary people to inject new vitality into the historical culture and art has become the inevitable trend and focus of the development of the times.

\section{THE DESIGN AND DEVELOPMENT OF THE CULTURAL AND CREATIVE WORKS OF "TRADITIONAL CHINESE CALLIGRAPHY TOOLS" IN THE DIGITAL ERA}

\section{A. Design philosophy}

The "traditional Chinese calligraphy tools" represent an epitome of Chinese culture for thousands of years. Since ancient times, many poems, calligraphy and paintings have been displayed by the traditional Chinese calligraphy tools, so that we can still have the opportunity to understand the charm of history and culture. Although the traditional Chinese calligraphy tools are no longer the main means of cultural communication, they have gradually grown into an art form. traditional Chinese calligraphy tools have become a way of cultural activities for people to cultivate their sentiment, and also a must in the life of painting and calligraphy masters.[1] In other words, the traditional Chinese calligraphy tools are not only not submerged by the rising tide of the new era, but also possess their unique cultural value. In the long history of China, what the traditional Chinese calligraphy tools represent is not only the traditional tools of Chinese calligraphy and painting, but also, more importantly, the important carrier of inheriting thousands of years of culture. In the 
long river of history, the traditional Chinese calligraphy tools carry the feelings and memories of generations of Chinese people. The Chinese people use them to convey emotions and write beautiful poems and chapters that can be passed down from generation to generation. For future generations, this spiritual civilization and cultural heritage are beneficial.

Today's digital age has witnessed the rapid emergence of knowledge products in the new era springing up like mushrooms, which are colliding with the ancient traditional culture. If we can promote the integration of different cultures and release the charm of this ancient culture, we will surely promote the pride and sense of mission of Chinese culture.

\section{B. Traditional Chinese calligraphy tools - the design, development and practice of cultural and creative design elements}

Cultural and creative products refer to the products that people use their own wisdom and skills to transform and upgrade the traditional cultural resources and cultural daily necessities, and enhance the value through the development and application of intellectual property rights [2].

Cultural and creative works are the product of the integration of life needs and art, and their design can be divided into two categories: one is cultural and creative life products, such as handicrafts in daily life, creative craft goods, etc.; The second is the cultural and creative products with distinct local characteristics, such as the items developed in collaboration with the art museum and tourism area. The value of the design of cultural and creative products lies in letting the masses better understand the cultural connotation beyond the object's own value. From the perspective of continuation and inheritance of traditional Chinese culture, this project adheres to the principle of "innovative aesthetics, inheritance of culture", and carries out element extraction, analysis and development design of the pen mountain and pen holder in the four treasures of classical culture. Focusing on cultural and creative design, this paper combines Chinese cultural characteristics to carry out research and development, and presents works through cultural and creative products, illustrations with Chinese historical and cultural colors and a series of peripheral products. I hope this design can make contribution to let more people enter the four treasures of study, and to the inheritance of the latter.

The theme of the project is "Shan Hai Wen Yuan". The design theme is based on 5000 years' thinking of Chinese culture. Chinese culture runs a long history, and its cultural deposits are as high as mountains (Shan) and as deep as the sea (Hai). In order to show its cultural origin, the project was named "Shan Hai Wen Yuan". After determining the theme, the corresponding logo design also began to expand. The "mountain" and "sea" in "Shan Hai Wen Yuan" are extracted and recreated by the combination of geometric elements, and the contour of the cultural and creative products is extracted. By integrating the geometric patterns of "mountain" and "sea" with the geometric patterns of the cultural and creative shapes, the logo form is established.

The font of logo is also closely related to the theme: extract and recreate the elements of "mountain" and "sea", simple and clear. Under the designed font, the Chinese Pinyin of Shan "Hai Wen Yuan" is directly expressed, which makes the whole more towards the aesthetic appeal of the contemporary people.

In a word, the overall logo, with distinct visual characteristics, broke people's traditional impression of the traditional Chinese calligraphy tools. Besides, the innovation, recognition and symbolism achieved by the logo are more in line with the aesthetic appeal of contemporary people and play the role of conveying the core vision. The logo design is as follows ("Fig. 1"):

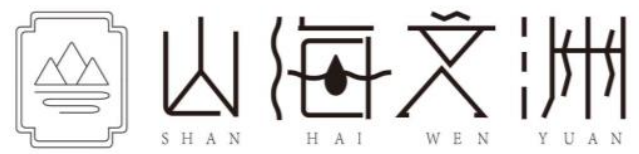

Fig. 1. Design drawing of logo.

Next is the main body of the product - the penholder design in the traditional Chinese calligraphy tools room. Starting from the project theme "Shan Hai Wen Yuan", the design closely follows the main idea: extract the elements of "mountains" and "seas" for analysis, development and creation.

In the design, the element shape of "mountain" is extracted, and combined with contemporary people's aesthetic demand for simplicity, the shape of "mountain" is reorganized to create a simple geometric pattern. The simple geometric figure is used as the pen mountain in the cultural and creative products to provide users with a place to place the brush when they learn calligraphy, as shown in the "Fig. 2".

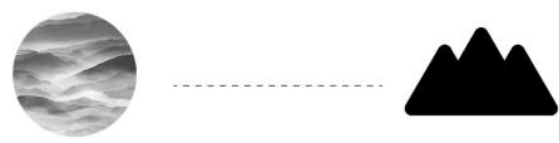

Fig. 2. Design ideas of cultural and creative products.

As early as in the Tang Dynasty, among the literati, the study of the literati can also be referred to as the room for books, such as Yuan Zhen's (Yuan Zhen (779831), styled Wei Zhi and born in Henan Province, was a 
famous poet in the Tang Dynasty). Therefore, based on the characteristic culture of the traditional Chinese calligraphy tools, the elements of "study" are extracted and recreated, and "study" is also defined as geometric patterns on the premise of the contemporary simple aesthetic appeal. [3] In this way, a simple geometric representation of cultural and creative products is realized. At the same time, on this basis, the top part of the cultural and creative products is perforated design and interspersed with lines, so as to achieve the versatility of cultural and creative - hanging brush.

In order to embody the inheritance and continuation of Chinese characteristic culture, on the basis of this work, an element with Chinese cultural characteristics - auspicious clouds is used to decorate the whole cultural creative product. Similarly, the characteristic element of "auspicious clouds" has also been analyzed and displayed in cultural and creative product through simple lines.

Finally, the combination of "pen mountain", "the study" and " auspicious clouds" is carried out to obtain the basic form of the work. Disc design is adopted at the bottom of the cultural and creative product, which makes the whole work more solid and practical, as shown in the following figure ("Fig. 3"):

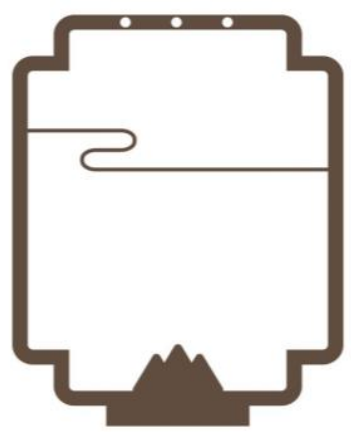

Fig. 3. Concept design drawing of the cultural and creative product.

The overall cultural and creative product is made of wood, "auspicious clouds" is expressed through alloy metal, and the final product is decorated with ornaments full of Chinese cultural atmosphere. The design adheres to the creative inspiration of "innovative aesthetics, inheritance of culture" and deduces contemporary cultural life. It is expected that through this project, the Chinese traditional culture and craft which are gradually getting away from each other will be preserved and integrated into the contemporary and future life through the modern aesthetic interpretation.

Pen holder is the main carrier of the four treasures in the study. The design of pen holder in this project is inspired by Bauhaus' simple design. For the pen holder, the project also introduces the design of ink bottle. The traditional ink bottle is inconvenient to use, because it must carry ink sticks and inkstone. After being improved, it is more portable, but it lacks aesthetic sense. The project adopts a new design concept to design these three different objects. In terms of color, the design is mainly presented in light gray, and the presentation of the main logo has greatly improved the aesthetic. ("Fig. 4")

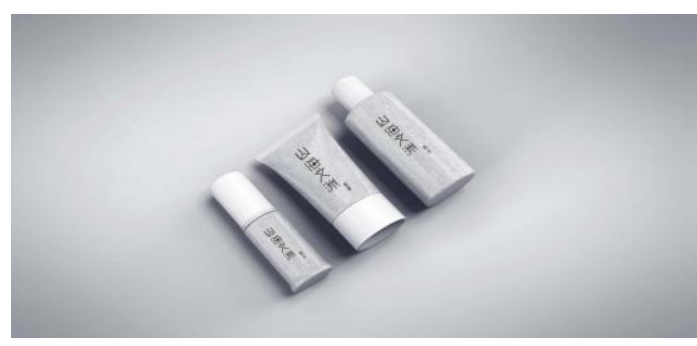

Fig. 4. "Shan Hai Wen Yuan" ink bottle design.

To make good products, the design of mature peripheral products plays an important role, because good peripheral products can improve the design style of products and product sales. The digital era is more inclusive of the young cartoon image, having a young cartoon image is conducive to the sales and promotion of products. This design can extract a representative design image, such as: $Q$ version of the cartoon character image, to narrow the distance between people and products. Taking many outstanding literati in Chinese history as the prototype, on the basis of which the image features are designed in $\mathrm{Q}$ version, and are endowed with different postures, expressions and movements in combination with the current hot issues, making the characters witty enough. In the traditional impression, people will think that the literati are stuffy and elegant, and this design is just to break these impressions, which will attract more attention of young groups.

The illustration takes the sky as the background, and makes it more colorful by using the gradual change effect of color. This broke people's traditional impression of color in Chinese calligraphy and painting - traditionally, people's impression of Chinese calligraphy and painting is that the color is single, black or white - and made the whole more in line with people's diverse appeals to color.

The scene of the illustration never deviates from the theme, and it makes use of "mountain" and "sea" as well as other traditional Chinese cultural elements, such as cranes, auspicious clouds and floating mountains, and draw them in combination.

The following is the illustration of "Shan Hai Wen Yuan" ("Fig. 5"): 


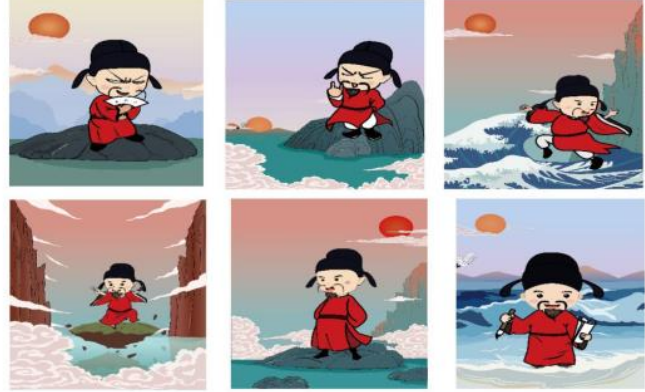

Fig. 5. Illustration of "Shan Hai Wen Yuan".

\section{The design prospect of cultural and creative products}

In recent years, with the continuous improvement of people's aesthetic taste and requirements for the quality of cultural life, as well as the characteristics of high tolerance of cultural inheritance and high return on investment, the cultural and creative industry is gradually developing into an emerging industry with great potential in China and gradually becoming a growing consumer hotspot. In view of this market prospect, many excellent cultural and creative products are pouring out one after another, and more and more people devote themselves to the design and development of this industry.

In recent years, the Guiding Opinions on Promoting the Development of the Four Treasures of Study issued by the Ministry of industry and information technology also fully shows the importance of the inheritance and development of the traditional Chinese calligraphy tools. Therefore, it is of great significance to innovate and develop the cultural and creative products of the traditional Chinese calligraphy tools for the protection and promotion of the excellent traditional culture of the Chinese nation.

The traditional Chinese calligraphy tools, as one of the outstanding traditional Chinese culture, are endowed with distinctive national characteristics and humanistic feelings, and play a crucial role in cultural inheritance. If we can further promote the development and investment of this cultural industry in the future, it will greatly promote the Chinese people to stick to the roots of traditional culture and inherit the national spirit. In the future, with the support of a series of favorable policies of the state, the development and listing of high-quality cultural and creative products will promote the economic development of cultural and creative industry, make contributions to the inheritance of Chinese culture, and raise the international awareness of Chinese culture. From these aspects, the market potential of this industry is huge and the prospect cannot be underestimated.

\section{CONCLUSION}

Today's digital age has witnessed the rapid emergence of knowledge products in the new era springing up like mushrooms, which are colliding with the ancient traditional culture. In order to promote the integration of different cultures, the development of cultural and creative design of the traditional Chinese calligraphy tools can promote the economic development of cultural and creative industry on the one hand, and on the other hand, it can also make more people to participate in the inheritance and development of calligraphy civilization. In addition, through the practice and promotion of this design project, we hope to release the new charm of the ancient culture of the traditional Chinese calligraphy tools and enhance the pride and sense of mission of Chinese people towards the Chinese culture.

\section{References}

[1] Gao Chengshan. Character in the traditional Chinese calligraphy tools - On the Unity of Pen, Ink, Paper and Inkstone [J]. Journal of Central China Normal University (Issue of Humanity and Social Science), 2006(S1):160-162.

[2] Chu Jiajun. Survival Path and Breakthrough of "Four Treasures of Study" in Digital Age [J]. China Newspaper Industry, 2018, No.445(12):95-96.

[3] Zhang Jun. A Brief Comment on For Treasures of the Study[J]. popular literature, 2011(17):290-291.

[4] Zhang Chengcheng. Research on the Design Concepts and Principles of Museum Cultural and Creative Products [J]. Art Gallery, 2018 (4Z): 247-249.

[5] Tang Jinghua, Cui Zuoqing. Design and Exploration of Campus Cultural Creative Products [J]. Journal of Qiqihar University (Philosophy and Social Science Edition), 2017 (8): 147-149.

[6] Wu Yixin. Research on the Development Strategy of Cultural and Creative Products - Taking Museum as an Example [J]. Packaging World, 2018 (9): 1-2.

[7] Yi Le. On the Development and Management of Cultural and Creative Products in Small and Medium Museums [J]. Popular Literature, 2013 (18): 66-68.

[8] Zheng Wenwen, Chen Liuqin. Copyright Game Analysis of Cultural and Creative Products [J]. Industry and Economic Review, 2012 (4): 66-71.

[9] Bai Yuan, Guan Yue, Li Yi. International Comparison of Trade Dependence of Cultural and Creative Products [J]. International Economic Cooperation, 2013 (2): 10-13.

[10] Ma Yajie. Research on Creative Design of Cultural Products of Henan Museum [J]. Beauty and Times: Part One, 2013 (6): 3134. 